\title{
К ПРОБЛЕМЕ СООТНОШЕНИЯ ТЕРМИНОВ «ДОМАШНЕЕ НАСИЛИЕ» И «НАСИЛИЕ В СЕМЬЕ»
}

\begin{abstract}
МАЛИНОВСКАЯ Татьяна Николаевна - кандидат юридических наук, доцент, ведущий научный сотрудник научно-исследовательской лаборатории проблем противодействия преступности Харьковского национального университета внутренних дел
\end{abstract}

https://orcid.org/0000-0002-7713-7617

УДК 343.9:343.226 (477)

DOI 10.32782/EP.2020.3.14

Рассмотрена правовая природа термина «насилие» как асоциальное явление. Проанализированъ понятия «насилие в семье» $и$ «омашнее насилие» как в международно-правовых актах, так и на уровне национального законодательства. Акцентировано внимание на определении понятия «семья» $и$ «члень семъи». На основе мнений и взглядов ученъх, исследовавших указанную проблематику, предложено собственное определение термина «домашнее насилие»

Ключевъе слова: домашнее насилие, насилие в семье, семья, член семьи, насилие по половому признаку, супруги.

\section{Введение}

Проблема домашнего насилия чрезвычайно важна прежде всего потому, что семья является основной ячейкой общества и поэтому должна находиться под особой защитой государства. Насилие и жестокость в семье не только разрушают гармонию и согласие в ней, но и выступают одной из предпосылок преступности в обществе в целом.

Государство - основной субъект противодействия насилию, поскольку органы государственной власти должны способствовать созданию обстановки неприятия насилия, принимая необходимые меры и создавая систему защиты жертв, наказания обидчиков и предотвращения насилия.

Несмотря на существующее нормативноправовое обеспечение в сфере противодействия и защиты прав и интересов лиц, пострадавших от домашнего насилия, а также значительное количество научных работ, по- священных различным аспектам этой проблематики, проблема домашнего насилия не теряет своей актуальности. И, в первую очередь, требует теоретического осмысления и уточнения, а также надлежащего обоснования категориального аппарата по указанной тематике, в частности учитывая неоднозначность терминов «домашнее насилие» и «насилие в семье».

В научной статье рассматривается природа термина «насилие» как асоциального явления. Проанализированы понятия «насилие в семье» и «домашнее насилие» как в международно-правовых актах, так и на уровне национального законодательства. Акцентировано внимание на определении понятия «семья» и «члены семьи». На основе мнений и взглядов ученых? исследовавших указанную проблематику? предложено авторское определение термина «домашнее насилие».

Ключевые слова: домашнее насилие, насилие в семье, семья, член семьи, насилие по признаку пола.

Постановка проблемы

В последние годы в Украине уделяется большое внимание проблемам предотвращения и противодействия домашнему насилию, которое приводит не только к потере самого дорогого для человека - жизни и здоровья, но и наносит большой социальный и моральный вред обществу.

Современный подход к проблеме домашнего насилия включает, с одной стороны, укорененность этой проблемы в общественном сознании как межличностного, а с другой - выходит из обязанностей государства гарантиро- 


\section{Кримінальне право, кримінальний процес та криміналістика}

вать права человека во всех сферах жизни, в том числе и в сфере семейных отношений.

Причины насилия, прежде всего, связанные с экономической ситуацией, падением нравов и равнодушным отношением к насилию. Насилие чаще всего считается частным делом, и поэтому даже сами жертвы не всегда сообщают о насилии в правоохранительные органы. Несообщение о фактах насилия, в свою очередь, не позволяет провести расследование, привлечь к ответственности и наказать обидчика так, как этого требует закон. Большинство случаев не доходят до суда, а когда доходят, то преступники, как правило, получают минимальное наказание [1, с.13].

Насилие как асоциальное явление не только формирует трагические обстоятельства для многих людей, но и создает криминогенные ситуации, которые предшествуют уголовным преступлениям против безопасности, здоровья и жизни человека, в целом разрушают фундамент стабильности общества.

Совершенствование правовой оценки домашнего насилия во многом зависит от осознания общественностью и самими пострадавшими того, что насилие является противоправным явлением, а часто и преступлением.

Для криминологического осознания и как результат предотвращения домашнего насилия требуется отдельное исследования природы самого термина «насилие». Как отмечает А. Благая? «... при разработке основных теоретических основ предотвращения насилия в целом, и насилию в семье, в частности, следует исходить из многомерного объяснения этого феномена, в котором нет ведущей роли какого-то одного фактора или составляющей» [2, с. 250].

\section{Состояние исследования}

Проблемы предупреждения домашнего насилия в значительной степени исследовали ученые А. Бандурка, А. Благая, В. Витвицкая, А. Джужа, А. Завадская, А. Кормич,ᄉ. Крыжная, Н. Аавриненко, И. Аавринчук, К. Аевченко, А. Аеонтьева, Л. Аевицкий А. Матвиенко, Т. Мельник, Т. Минка и другие, однако несмотря на широкий круг научных исследований в сфере защиты прав человека от насильственных преступлений, вопрос соотношения терминов «насилие в семье» и «домашнее насилие» остается дискуссионным.
Целью научной статьи является разработка собственного определения термина «домашнее насилие». Задачей является анализ и сравнение терминов «насилие в семье» и «домашнее насилие» в их нормативно-правовом определении.

Научная новизна исследования заключается в обосновании собственного виденья содержательного наполнения термина "домашнее насилие» с учетом мнений и взглядов ученых, исследовавших указанную проблематику.

\section{Изложение основного материала}

Понятие «насилие в семье»? «домашнее насилие» используются в международно-правовых актах обязательного и рекомендательного характера, которые существуют на уровне ООН, Совета Европы и Европейского Союза. Среди них необходимо выделить Всеобщую декларацию прав человека 1948 г. [3], которая считается главным документом в области защиты прав человека. Декларация провозгласила принципы юридического равенства, а также запрет дискриминации по любым признакам, в т. ч. по признакам пола. В Декларации о ликвидации дискриминации в отношении женщин 1967 г., которая позже, в 1979 г., была заменена одноименной Конвенцией, отмечается, что должны быть приняты все надлежащие меры с целью подготовки общественного мнения на направления национальных стремлений к искоренению предрассудков, обычаев и всех других проявлений, основанных на идее неполноценности женщин [4]. Декларация об искоренении насилия в отношении женщин 1993г. признала насилием женщин любой акт насилия, совершенный на основании полового признака, который причиняет или может причинить физический, половой или психологический ущерб, страдания женщин, а также угрозы совершения таких актов, принуждение или произвольное лишение свободы в общественной или в личной жизни. В Декларации также говорится, что насилие к женщинам охватывают случаи физического, полового и психологического насилия, которые имеет место в семье [5].

Комитет ООН по ликвидации дискриминации в отношении женщин на 11 сессии принял Общую рекомендацию № 19 «Насилие в отношении женщин», в которой четко определил, что «насилие в отношении женщин представляет собой одну из форм дискриминации, 
серьезно ограничивает возможности женщин по использованию прав и свобод на основе равенства с мужчинами». Насилие в семье рассматривается как проявление насилия в отношении женщин, поскольку непропорционально влияет на женщин и именно женщины в большинстве случаев страдают от этого нарушения прав человека [6, с.11].

Организация Объединенных Наций определяет, что насильственные действия в семье охватывают все насильственные действия физического, психологического и сексуального характера в отношении женщин, совершенные по половым признакам лицом или лицами, которые связаны с ними родственными и близкими отношениями, от словесных оскорблений и угроз к тяжелым физическим побоям, похищениям, угрозам увечьям, запугиваниям, принуждению, преследованию, насильственному или незаконному вторжению в жилище, уничтожению собственности через поджог, сексуальному насилию, изнасилованию в браке, насилию, связанному с приданым или выкупом невесты, увечьям гениталий, эксплуатацией через проституцию, насилие в отношении домработниц и попытками осуществить такие акты. При этом все они должны рассматриваться как «насилие в семье» [6, с.12].

Модельное законодательство ООН положено в основу Закона Украины «О предупреждении насилия в семье», который был принят Верховной Радой Украины 15.11.2001 г. (прекратил свое действие 07.01.2018). Әтот Закон гарантировал охрану прав членов семьи при осуществлении мероприятий по предупреждению насилия в семье и определял организационно-правовые основы предупреждения насилия в семье; основания для принятия мер по предупреждению насилия в семье; полномочия органов и учреждений, на которые возлагается осуществление мер по предупреждению насилия в семье, и источники их финансирования; специальные меры предупреждения насилия в семье; ответственность за совершение насилия в семье и т.д. [7, с.36]. В Законе насилия в семье определено, как: «любые умышленные действия физического, сексуального, психологического или экономического направления одного члена семьи по отношению к другому члену семьи, если эти действия нарушают конституционные права и свободы члена семьи как человека и гражданина и на- носят ему моральный ущерб, вред его физическому или психическому здоровью».

Следует заметить, что при установлении содержательного наполнения понятия «насилие в семье» концептуально важным являются значения «семья» и «члены семьи».

Определение семьи содержится в ст. 3 Семейного кодекса Украины, где сказано, что: «Семью составляют лица, которые совместно проживают, связаны общим бытом, имеют взаимные права и обязанности. Супруги считаются семьей и тогда, когда жена и муж в связи с обучением, работой, лечением, необходимостью ухода за родителями, детьми и по другим уважительным причинам не проживают совместно. Ребенок принадлежит к семье своих родителей и тогда, когда совместно с ними не проживает. Семья создается на основании брака, кровного родства, усыновления, а также на других основаниях, не запрещенных законом и не противоречащих моральным устоям общества» [8].

И. Тимуш, при исследовании в правовом и социальном аспекте термина «семья», рассматривает его в двух направлениях. Первое направление правовых исследований заключается в том, что семья не рассматривается в юридическом аспекте, «поскольку субъектом семейного права является не семья, а конкретные лица (супруги, дети, родители)». Социальная составляющая подчеркивается широтой критериев, характеризующих семью и отличием условий существования семей. Второе направление правовых исследований заключается в том, что социальные отношения регулирует именно право, несмотря на то, что семья является социальной категорией. Поэтому, семейные отношения приобретают правовое содержание и становятся правоотношениями, предоставляют правовой статус семьи.

И. Тимуш отмечает, что семью в правовом смысле целесообразно рассматривать как юридическую связь между физическими лицами. Применение понятия юридическая связь четко подчеркивает смысловую нагрузку, указывающую на семью как правовую категорию и четко отделяет юридическое определение семьи от социологического. Юридическая связь является ничем иным как правоотношениями, возникающими между членами семьи на определенных законом основаниях [9, с.111]. 


\section{Кримінальне право, кримінальний процес та криміналістика}

Членами семьи могут быть: супруги; родители (мать, отец) и ребенок (дети); усыновители (усыновитель) и усыновленный (удочерена), дед (бабушка) и внук (внучка), отчим (мачеха) и пасынок (падчерица), братья и сестры, фактические воспитатели и воспитанники. Членами семьи могут быть признаны также и другие лица, являющиеся родственниками и вместе проживающие. Необходимо учитывать, что сыновья и дочери принадлежат к семье своих родителей и тогда, когда совместно с ними не проживают. В соответствии с Законом Украины «О предупреждении насилия в семье» определено, что члены семьи - это лица, которые находятся в браке; проживают одной семьей, но не находятся в браке между собой; их дети; лица, находящиеся под опекой или попечительством; являются родственниками прямой или непрямой линии родства при условии совместного проживания [10, с. 149].

Толкование понятия «член семьи» дается в п. 6 Решения Конституционного Суда Украины от 03.06.1999 г. №5-рп / 99, в котором содержится разъяснение по этому поводу. Конституционный Суд Украины исходит из объективных отличий в его содержании в зависимости от отрасли законодательства (п.6). Таким образом, по мнению Конституционного Суда, определить единое понятие «член семьи», которое должно применяться в праве, невозможно, потому что каждая отрасль права толкует это понятие по-своему, подчеркивая те или иные признаки семьи, которые приобретают определенное значение для других отношений. По мнению И.В. Жилинковой в основу определения семьи должны быть положены лишь главные признаки, по которым семья рассматривалась бы именно как юридический феномен: «в юридическом определении семья - это объединение лиц, связанных между собой общностью жизни и взаимными правами, и обязанностями, которые возникают на основаниях, предусмотренных в законе» [11, с. 51]. Исследовательница определяет, что членом семьи необходимо считать как ближайшее лицо, так и другого человека, с которым вместе живут или ведут хозяйство. Вместе с тем, Семейный кодекс Украины не включает в членов семьи бывших супругов, даже при условии совместного проживания.

В Конвенции Совета Европы о предотвращении и борьбе с насилием в отношении женщин и домашним насилием (Стамбуль- ская конвенция), под термином «домашнее насилие» подразумеваются, все акты физического, сексуального, психологического или экономического насилия, совершаемые в семье на бытовом уровне, между бывшим и нынешним супругами, партнерами, независимо от того, проживает правонарушитель с жертвой или нет [12].

Постановлением Кабинета Министров Украины «О внесении изменений в постановление Кабинета Министров Украины от 5.09.2007 № 1087 «О консультативно-совещательных органах по вопросам семьи, гендерному равенству, демографическому развитию, предотвращению насилия в семье и противодействию торговле людьми», термин «насилие в семье» было заменено на «домашнее насилие». На законодательном же уровне этот термин был использован Верховной Радой Украины 07.12.2017 г. при принятии Закона Украины № 2229-VIII «О предотвращении и противодействии домашнему насилию», который изначально был нацелен на реформирование отечественной системы предупреждения и противодействия домашнему насилию и насилию по признакам пола. Статьей 1 Закона определено, что домашнее насилие - это деяния (действия или бездействие) физического, сексуального, психологического или экономического насилия, совершаемые в семье, или в пределах места жительства, или между родственниками, или между бывшим или нынешним супругами, или между другими лицами, которые совместно проживают (проживали) одной семьей, но не находятся (не состояли) в родственных отношениях или в браке между собой, независимо от того, проживает (проживало) лицо, совершившее домашнее насилие, в том же месте, что и пострадавшее лицо, а также угрозы совершения таких деяний. [13].

При этом деяние признается насилием лишь тогда, когда оно нарушает требования действующего законодательства и приводит или может привести к нарушению конституционных прав и свобод члена семьи. Домашнее насилие может иметь форму как активных действий (нанесение побоев, уничтожение имущества), так и бездействия, то есть пассивного поведения лица, когда оно не совершает действий, которые могло и должно было сделать, чтобы предотвратить наступление вредных последствий (например, неоказание по- 
мощи члену семьи, находящемуся в опасном для жизни положении).

Заметим, что при определении домашнего насилия, как социального явления, такие термины, как: насилие в семье, семейное насилие, насилие по признаку пола, домашнее насилие, внутрисемейное насилие обычно употребляются в качестве эквивалентных, а в ряде случаев они сочетаются с понятием бытового насилия. Именно поэтому и возникает вопрос о смысловом содержании и соотношении указанных терминов.

На первый взгляд, действительно принципиальных различий между содержательной нагрузкой данных терминов не существует. Однако более пристальный анализ позволяет выделить ряд различий. По мнениюС. Максимова и В. Ревина, «бытовое насилие» как преступления «на почве конкретно личностных, непроизводственных отношений, конфликтов, мотивированных неприязнью, завистью, ревностью или хулиганскими действиями виновного, связанного с потерпевшим семейным или соседским общением» $[14$, с. 27]. По данному утверждению понятно, что взаимосвязь «преступник-жертва» здесь не обязательно предполагает наличие семейных отношений. Более того, мы бы дополнили данное определение тем, что для оценки преступления как бытового не нужно длительного и устойчивого межличностного общения, как это предусмотрено при квалификации домашнего насилия.

Как заявляет Ф. Меликов, ключевой составляющей термина «домашнее насилие» является слово «домашнее», что относится к дому, то есть его этимологическая сущность означает «жилище и людей, живущих в нем», это могут быть как члены семьи, так и другие лица, отношения которых сложились в доме. То есть территориальный признак этого понятия является определяющим [15, с. 29-30].

На взгляд автора данной статьи, определяющей составляющей термина «домашнее насилие» является неограниченное место совершения насильственных действий (здание или другая придомовая территория), а субъекты таких посягательств. В данном случае «домашнее» - прилагательное, которое касается дома, но при этом аспекте определяющими являются отношения и юридический статус лиц, которые охватываются понятием «семья». Необходимо, учитывать и тот факт, что на одной территории могут проживать несколько семей, и может быть совершено насильственное преступление между соседями, но такое преступление не будет рассматриваться как домашнее насилие. По мнению А. Гумина, термин «домашнее насилие» является несколько нечетким и не указывает участников такого насилия, ограничивая насильственный акт домашней территорией. Понятия «насилие в семье» и «семейное насилие», принимаемые как синонимы, являются расширенными, содержащими все аспекты агрессивного принудительного воздействия, наносящие различные убытки члену семьи, и распространенные в международных актах [16, с. 496].

Т. Минка определяет, что для квалификации ст. 126-1 Уголовного кодекса Украины имеет значения проживает ли правонарушитель в момент совершения деяния в том же месте, что и потерпевший. Очень часто домашнее насилие может происходить и после разрыва семейных или других отношений, поэтому совместное проживание жертвы и правонарушителя не требуется $[17$, с.100].

Именно поэтому имплементация в массив уголовного закона Украины понятия «домашнего насилия» как отдельного вида уголовного преступления вызывает немало научных дискуссий. Прежде всего, это касается дублирования одного и того же понятия «домашнее насилие» в различных интерпретациях, которые содержаться в положениях Закона Украины «О предотвращении и противодействии домашнему насилию» и в Уголовном кодексе Украины. Такой подход законодателя, с одной стороны, кажется оправданным, с целью подчеркнуть особенности домашнего насилия именно как уголовного преступления, но, с другой стороны, наличие двух различных законодательных дефиниций и отсутствие терминологического единства, являются противоречащим правилам законодательной техники; во-вторых, в определенной степени усложняющих практику применения соответствующих положений УК Украины; в-третьих, не способствующим четкости ведения статистического учета для количественной оценки совершенных уголовных преступлений, связанных с домашним насилием, в конце концов не способствующим адекватному планированию мероприятий по противодействию этому деянию. 


\section{Кримінальне право, кримінальний процес та криміналістика}

Подводя итог, следует отметить, что содержание домашнего насилия опосредуется через продолжающиеся отношения между близкими людьми, связанными общим бытом или родственными связями.

В отличие от преступления, совершенного незнакомым человеком, домашнее насилие исходит от супруга или партнера, жены, бывшего мужа, бывшей жены, родителей, детей, других родственников.

С учетом вышеизложенного, можно предложить следующее определение - домашнее насилие - это акты умышленного систематического совершения противоправного физического, психологического, сексуального, экономического влияния на близких людей, которые осуществляются против их воли с целью достижения власти и контроля над ними, что приводит к разного рода страданиям, расстройствам здоровья, эмоциональной зависимости или ухудшению качества жизни потерпевшего.

\section{\итература}

1. Конвенція Ради Европи про запобігання насильству стосовно жінок і домашньому насильству та боротьбу із цими явищами (Стамбульська конвенція) Довідник для членів парламенту, 2013. - 108 с. URL: https://rm.coe.int/1680096e45 (дата обращения: 07.09.2020).

2. Блага А.Б. Дослідження соціальної природи насильства - теоретичне підгрунтя для кримінологічного аналізу насильства в сім’ї // Порівняльно-аналітичне право. № 3-2. 2013. C. 247-250.

3. Загальна декларація прав людини від 10 грудня 1948 року // Офіційний вісник України. - 2008. - № 93. - Ст.3103

4. Комітет економічних, соціальних і культурних прав : Документ ООН Е/С.12/1995/15 від 8 груд. 1995 р. - П. 25.

5. Декларация об искоренении насилия в отношении женщин: Міжнародний документ від 20 груд. 1993 р. - URL: http://zakon3.rada. gov.ua/laws/show/995_506. (дата обращения 10.08.2020)

6. Моніторинг стану виконання законодавства України щодо протидії насильству в сім'ї. 2001-2011 роки / Кол. авт.: О.М. Бандурка, О.Ф. Бондаренко, В.О. Брижик, та ін.; заг. ред. О.М. Бандурки, К.Б. Аевченко; вступ. слово О.О. Зарубінського . Х. : Видавництво «Права людини». 2011. 240 с.

7. Ткаленко О. М. Нормативно-правове забезпечення попередження насильства в сім’ї в Україні: стан та перспективи розвитку // Південноукраїнський правничий часопис.№ 3. 2014. С. 35-38.

8. Сімейний кодекс України : Закон України від 10.01.2002 № 2947-III // Відомості Верховної Ради України. 2002. № 21-22.CiT. 135.

9. Тімуш I.C. Визначення сім'ї у юридичній науці // Юридичний вісник. Повітряне і космічне право. № 2 (47). Київ. 2018. C. 109-115.

10. Череваш О. М. Адміністративноправова характеристика насильства в сім’ї // Право і суспільство. № 6 . 2011. С. 147-151.

11. Насильство в сім'ї (кримінологічний аналіз і запобігання): монографія / А.Б. Блага. - Х. : ФО-П Макаренко. 2014. 360 с.

12. Конвенція Ради Европи про запобігання насильству стосовно жінок і домашньому насильству та боротьбу із цими явищами: Міжнародний документ від 11 травн. 2011 URL: https://ips.ligazakon.net/ document/view/MU11251 (дата обращения 10.08.2020)

13. Про запобігання та протидію домашньому насильству: Закон України від 07.12.2017 № 2229-VIII. URL: http://zakon3. rada.gov.ua/laws/show/2229-19 (дата обращения: 16.06.2020).

14. Максимов С.В., Ревин В.П. Насильственные преступления в сфере семейно-бытовых отношений и проблемы их профилактики: учебное пособие. М., 1993. - 56 с.

15. Меликов Ф.А. Уголовно-правовые и криминалогические меры противодействию насилия в семье. Дисерт. канд. юрид. наук: 12.00.08. М. 2017. 181c.

16. Гумін О.М. Кримінологічна характеристика насильства у сім'ї щодо неповнолітніх. 2016. C. 492-499 UKR: http://science.lpnu.ua/ sites/default/files/journal-paper/2017/aug/5774/ vnulpurn201685074.pdf (дата обращения: 03.09.2020)

17. Мінка Т. Розмежування адміністративної та кримінальної відповідальності за вчинення домашнього насильства // Нац. юрид. журнал теорія та практика. 2019. С. 98-101. 


\section{АННОТАЦИЯ}

Домашнее насилие считается одним из самьгх распространенньлх и грубейших нарушений прав и свобод человека - женщин, мужчин, пожильхх людей, детей. Практически во всех странах мира различнве общественнъле организаиии и органъг государственной власти, так или иначе, занимаются этой проблемой, акцентируя внимание на ее латентности и укорененности в глубинньгх пластах массовъгх представлений о взаимоотношениях людей в семье.

Для криминологического осознания домашнего насилия необходимъим является отельное исследование соотношения понятий «насилие в семье» $и$ «домашнее насилие», которьие использунтся в международно-правовъхх актах обязательного и рекомендательного характера и существуют как на уровне ООН, так и Совета Европьг и Европейского Союза.

Проблема предотвращения домашнего насилия, устранения его причин и условий остается актуальной и для Украинъ, ведь экономический кризис, и сложнье сочиально-политические процессы усиливают негативнье аспекты семейньх отношений и существенно влияют на производньле от нее институтьл. В частности, изменились стандартьи, когда основой семьи считался обициально зарегистрированньлй брак, увеличилось количество семей, проживающих за чертой бедности, распространились боновъие явления - алкоголизм, наркомания, проститущия, уменьшились возможности влияния на семъю общественностью и т.д.

Отмечается также несовершенство законодательства, призванного регулировать семейнье взаимоотношения. Между тем, именно правовое обеспечение призвано упреждать случаи домашнего насилия и гарантировать его пробблактику, то есть - защиту прав и свобод человека в кругу семьи. Усовершенствования правовой оценки домашнего насилия во многом зависит от осознания общественностью и пострадавшими того, что насилие является противоправнъл явлением, а в большинстве случаев и преступлением.

B статье рассматривается понятие «домашнее насилие», закрепленное сегодня в украинском законодательстве, с учетом его анализа через призму соответствия международнъмм стандартам в этой сбере и зарубежнылми практиками их приложения тем более, что сами понятия «насилие в семье» $и$ «домашние насилие» до настоящего времени въъзивают оживленнье дискуссии как научного, так и правового характеpa.

Автором рассмотрено теоретическое осмьлление, уточнение, а также надлежащее обоснование категориального аппарата по указанной тематике.

\section{SUMMARY}

Domestic violence is currently considered by the international community to be one of the most widespread and gross violations of human rights and freedoms - of women, men, the elderly, and children. Practically various public organizations and public authorities in all countries of the world, one way or another, are dealing with this problem, publicly exposing its latency and complexity, archaic rootedness in the deep layers of mass ideas about the relationship of people in the family.

For the criminological understanding of domestic violence, it is necessary to study separately the correlation between the concepts of "domestic violence" and "violence in the family", which are used in the international legal acts of a binding and recommendatory nature and exist both at the level of the UN and the Council of Europe and the European Union. Many scientific works in various aspects are also focused on terminological meanings.

The problem of preventing domestic violence, eliminating its causes and conditions remains relevant for Ukraine, because the economic crisis and complex socio-political processes intensify the negative aspects of family relations and significantly affect the institutions derived from it. In particular, the standards have been changed, when an officially registered marriage was considered the basis of the family, the number of families living below the poverty line increased, background phenomena like alcoholism, drug addiction, prostitution were spread, the possibilities of influencing the family by the public, etc.

The imperfection of the legislation assigned to regulate family relationships is also noted. Meanwhile, it is legal provision is assigned to prevent cases of domestic violence and guarantee its preventive activities, that is, the protection of human rights and freedoms in the family. Improvement of the legal assessment of domestic violence largely depends on the awareness of the public and the victims themselves that violence is illegal phenomenon, and in most cases it is a crime.

The author of the article discusses the concept of "domestic violence", currently enshrined in Ukrainian legislation, taking into account its analysis through the prism of the compliance with international standards in this area and international practices of their application, especially since the concepts of "domestic violence" and "violence in the family" still cause lively discussions of both scientific and legal nature.

The author has studied theoretical comprehension, clarification, as well as the proper substantiation of the categorical apparatus on the indicated topic.

Keywords: domestic violence, domestic violence, family, family member, gender-based violence, spouses. 